\title{
Some Considerations on the Issue of Economic and Social Sustainability
}

\author{
Giovanni Antonio COSSIGA \\ Correspondence: ex Presidente Collegio sindaci Policlinico Umberto 1, Università Sapienza - ROMA
}

Received: March 10, 2021

Accepted: April 30, 2021 Online Published: May 12, 2021

doi:10.5539/res.v13n2p97

URL: https://doi.org/10.5539/res.v13n2p97

\begin{abstract}
To be implemented and analyzed, according to the good rules of relationship with nature, sustainability must be equipped with a theoretical scheme able of helping to understand the dynamics of this relationship together with the opportunities offered to improve the development of the economic system. Essentially, it's about acknowledging that, just like physics, also the economy is subject to some general and abstract laws. This is the case of the core inflation value, defined by Central Banks as a value close to $2 \%$. So, if the economy moves along the track indicated by this value, we have confirmation that growth is regularly developing. This core inflation value is implicitly defined without a clear specification. We can therefore admit that it's an ideal value like the great universal constants, which reports about an economic system that develops according to the rules of natural compatibility. According to this point of view, the core inflation close to $2 \%$ is essentially a utopia, because it can only be achieved if the global economic growth moves in full accordance with the nature around us. It follows that even if we can verify on field the realization of a base value close to $2 \%$, actually we are not in the best conditions, especially if the global economy is suffering from deflation as today. The deflation, that is the tendency of prices to fall, is part of the complex messages sent by the nature and economic systems to signal that the economy is not doing well and has become unstable. Both inflation and deflation are messages that never contribute to the economic development course, but they are born and evolving in parallel with the appearance of the economic cycle in daily activity. In summary, a mechanism that has the responsibility, by imposing pauses on the system, to reduce the instability of the systems and to facilitate the return to the natural development condition. A correction system based on the economic conjuncture that obviously distinguishes the stability by the way that the economy grows and develops in a linear and constant inclination depending on differentials.
\end{abstract}

Keywords: economic system instability, inflation, deflation, conjuncture cycle, balance with nature

\section{Introduction}

\subsection{The Instability of the Economy and Its Messages to the Community}

The sustainability in economics must be understood as the relationship between humanity with its economic and social activities, and the nature around us. According to this evaluation parameter of economic and social relations, we should admit that the relationship with nature may sometimes not be optimal. But it's in some way undermined, indeed, by the pressure exerted by human beings in the non-rational use of natural resources. If this relationship with nature is deviated, the economy has lost the path of compatibility with nature and is thrown into an instability sub-world.

We can certainly say that a large part of the global economy today is into this condition of economic instability. But with what consequences at the level of everyday life? The first and decisive exception is the presence inside the economic systems of a non-linear but sinusoidal conjuncture development. In other words, the economic growth follows the ups and downs of the conjuncture cycle. A recovery phase in any case is followed by a recession or reduction phase in gross product. Not only that: if the instability continues; the pace of the economy changes for the worse in the sense that the recovery phase is increasingly reduced when the equilibrium relationship with nature is worsening. In the meantime, the declining trend in Domestic Product (GDP) is extended over time and the economy contracts, then causing serious social and economic effects.

Therefore, the economic instability is very costly and to return to the stability and compatibility phase it's often necessary to support the natural process of correction. It follows that the normal operations of fiscal and monetary policy to boost the weak economy can give appreciable results if they do not oppose frontally to the natural work of correcting the unstable economy. Now, it's true that in the post-2008 financial crisis the use of extraordinary amounts of deficit spending avoided the worst damage of an uncovered financial crisis. However, we must say that this effect - certainly positive - was obtained because the financial policy on that occasion played a concomitant role in the natural process of rebalancing the economic systems. And particularly, the fiscal policy seems called upon to limit the consequences of a very unbalanced distribution of wealth to the detriment of that part of community less favored or even at a poverty level. Thus, the fiscal 
policy seems called upon to play a significant role in order to return to the least favored and poor part of the community a part (at least) of the wealth, which otherwise would flow (as usual) towards the wealthiest top part of society.

Obviously, there are some hidden sides of the maneuver. The first and directly observable, is the undue growth of public debt, which in turn means weakness for the most fragile systems, therefore more exposed to the recession wind. And unfortunately, this isn't the only dark side. The fact remains that fiscal policy is called upon to play an essential role which at least partially will compensate for the serious imbalances caused by the concentration of wealth in a few hands and the parallel spread of poverty.

Nevertheless, also the abnormal process dragging wealth upwards and then depressing the most disadvantaged population groups is another symptomatic effect of the imbalance of economic systems in their relationship with nature. Now, how can we say that an economic system is running in accordance with the natural compatibility? How can we say that we are on a correct path with the evolution of the planet which is feeding us?

Well, the first element to be observed is precisely the development trend: if it's growing correctly and constantly, or instead according to a sinusoid that changes sign and direction. So, if there is instability, then we will have the conjuncture cycle pace as a companion, together with a series of events such as anomalous wealth distribution and damage to the most disadvantaged classes. Unlikely, in the case of stability, understood as a long and compatible relationship with nature, the development of the economic system tends to rise slightly and steadily over time.

In other words, if the development path is compatible, we will have an economic growth that follows, without interruptions, a path slightly upward and constant over time. As saying that the advantages offered by the natural path of development compatibility are those sought by every good government really interested in social welfare. The problem is that once the path of imbalance and incompatibility has been taken, the suggestion is always to resort to the usual monetary and financial policy maneuvers, which are anyway unable to bring the deviated system back on the path of a correct relationship with nature.

The real problem is that the issue of sustainability and relationship with nature is often ignored. A relationship relying on the axiom of the use of natural resources. The resources offered by the nature should be used rather than exploited. The ultimate goal of human beings should be to preserve the natural resources for future generations. An irrevocable rule that finds its most direct expression in the stability of economic systems. Systems that, in the compatibility context, can grow at a steady, slightly upward pace. As saying that an orderly and constant development is possible, if we preserve the natural resources for future generations.

Therefore, to preserve the natural resources without exploiting or wasting them is an issue of respect for the rule that sees the future generations as those who have the task of following the path of knowledge of mother nature. In other words, humankind would always have the transcendent task of interpreting and understanding the universe around us: starting with the Egyptians and passing through the Maya who deified the sun, to finally get to a growing group of researchers seeking today the rules that allowed the construction of the universe and that are governing the solar system. Moreover, the entire community will be interested by the repercussions that the efforts of study and research can bring in terms of social and economic prosperity.

\subsection{The Instability Symptoms Globally Pervading the Economy}

In case of instability, the economic systems are subject to the conjuncture cycle, that is a corrective mechanism introducing the recession into the scenario. The recession is essentially a corrective mechanism which, when left to act, can allow the reduction of the anomaly and therefore the gradual return to stability and compatibility with nature. The correction mechanism par excellence is therefore the recession, although in the instability world other phenomena with different purposes take shape and evidence, such as the monetary anomalies.

As I have already explained in previous works (Cossiga, 2019), monetary anomalies such as inflation or deflation, are not active parts of the economic mechanism; that is, they do not participate in the economic development. They are instead messengers of an altered and unbalanced economic system, designed to signal at the community level that the economic system has left the path of balance with nature. From this point of view, they cannot be subject of reaction and opposition because they are just 'ghosts' created by the instability. While it's necessary, instead, to correct the reasons that led the economic system to diverge from the right path. On the other hand, the path indicated by the correct relationship with nature is certainly attractive. In fact, if it is followed without deviations, it will allow us to count on a constant and slightly rising economic growth.

A picture that we can define in terms of the "tomorrow as today" expectations, precisely because in the stability world the conjuncture cycle anomalies are excluded, in order to avoid periodic and recurring recessions or financial crises. The rupture of the relationship with nature, on the other hand, entails the appearance of the conjuncture with its erratic rhythms in the scenario. Then, the symmetry of a constant growth is dissolved to set in motion a risky path with efficiency loss and 
reduction of development capacity, which finally stops or anyway declines. (Geithner, 1914)

The intrinsic rule of the conjuncture cycle is exactly to curb the drive for constant development when the diverted economy risks compromising the self-correcting ability of nature. So, remain opaque all the attempts to solve anomalies in the economy with the usual remedies of fiscal and monetary policy, if the goal is the return to the stability steady growth. It would remain an unlikely goal, without correcting the instability underlying reasons or without correction of the status quo.

On the other hand, are far from irrelevant those monetary phenomena, such as inflation or deflation, which do not participate in the economic action, and are instead real messages informing the community that economic things are bad. These messages come from the market in explicit form, through the price trends (inflation or deflation) or in implicit form, as widespread sensations on the favorable or unfavorable economic condition.

Messages that are directed to the community, to favor the adaptation of its behavior to the changed conditions of the economic context, and above all to make evident a growing critical position towards the leaderships governing the economy. We must in fact remember that the community is the terminal point of the relationship between humanity and nature. In the sense that the community is the most sensitive to every change in economic conditions.

How to explain, on the other hand, the peculiar ability of the common man or our neighbor to summarize at a glance the economic situation; in order to agree with the action carried out by the economy management; or to show a critical attitude so to be able to understand, in a simplified and synthetic way, what to do to get out of the wrong path and return to the compatibility balance.

In other words, it could be said that the community decides, following the explicit or implicit messages coming from the economic system, what scenario the economy will develop in the future. A demonstration that the relationship between humanity and nature is strongly linked and that everything happens because of the shared will of the whole community.

According to this pattern of reflections, we can try to interpret the long story that has fueled a growing inflation at a global level since the 1970s, which was only apparently solved in the 1990s and then has turned into deflation, also widespread at a global level. Now, it seems evident that between the two realities, the world in inflation and the current one in deflation, there isn't a great discontinuity but instead a sort of continuity. In the sense that the world in inflation has somehow adapted to the world in deflation of the current scenario. But apart from the reasons for this transformation of monetary messages from the economic system, it is worth considering that since the seventies the economy at a global level is running in conditions of imbalance and incompatibility.

In other words, the monetary messages are changing to inform the community that things are going wrong in the economy but doesn't change the underlying problem about the general instability of economic systems. The long fight against inflation, previously held under a cautious control, did find its turning point for the initiative of the Fed president Volker and the US president during the late 1970s. The Fed decided to make the interest rates surge until $21.5 \%$. Under the strong tightening of monetary policy, the North American economy fell into recession in the years 1980-81. Inflation which, at the end of seventies, was running at $15 \%$, then was tamed and contracted to $5 \%$ to finally decline to $2 \%$ for the whole of the nineties. ${ }^{1}$

Inflation was tamed and the entire global economy followed the US road to eradicate inflation. However, thrown out the door, it came back in the form of deflation during the 2000s. We could assume that when the world learned to eradicate inflation and to block the reappearance of the nominal price run, then logic and modality of the message to community

\footnotetext{
${ }^{1}$ President Jimmy Carter nominated Paul Volcker to serve as chairman of the Board of Governors of the Federal Reserve System on July 25, 1979. He was confirmed by the U.S. Senate on August 2, 1979, and took office on August 6, 1979. President Ronald Reagan re-nominated Volcker to a second term in 1983.

Inflation emerged as an economic and political challenge in the United States during the 1970s. The monetary policies of the Federal Reserve board, led by Volcker, were widely credited by curbing the rate of inflation and expectations that inflation would continue. US inflation, which peaked at 14.8 percent in March 1980, fell below 3 percent by 1983. The Federal Reserve board led by Volcker raised the federal funds rate, which had averaged $11.2 \%$ in 1979, to a peak of $20 \%$ in June 1981. The prime rate rose to $21.5 \%$ in 1981 as well, which helped lead to the 1980-1982 recession, in which the national unemployment rate rose to over $10 \%$. Volcker's Federal Reserve board elicited the strongest political attacks and most widespread protests in the history of the Federal Reserve (unlike any protests experienced since 1922), due to the effects of high interest rates on the construction, farming, and industrial sectors, culminating in indebted farmers driving their tractors onto C Street NW in Washington, D.C. and blockading of Eccles Building. The US monetary policy eased in 1982, helping lead to a resumption of economic growth.
} 
was changed. Because we're anyway talking about message: a message that is suggesting to the community that things in the economy are going bad. When the deflation appeared, soon globally spread, starting from those countries most fragile from a financial point of view.

\subsection{Inflation or Deflation Are Just Messages, Images and They Cannot Be Adjusted by Direct Actions}

The fight against high inflation rates was done with the maneuvering of interest rates, through the monetary policy. An indirect action that works through interest rates, raising them in sequence, according to the inflation movements. The high interest rates discourage many economic activities due to the rising cost of money, then causing a cyclical reversal and the falling of economic system into recession. The recession of the economy produces the effect - somehow unavoidable - of contracting the run of nominal prices. If monetary tightening is maintained, at the same time the recession increases, and a parallel reduction is produced in the inflation rate.

In some way, therefore, the action of monetary policy moves in symmetry with the natural correction, which - through the conjuncture cycle - aims to correct the imbalance of the economy. Let us not forget that the conjuncture cycle introduces into the economic system the periodic recession phase, which is aimed to reduce the economic instability. In other words, it's about pausing the development mechanism to allow the reduction of the instability in the economic systems.

Now, it's certainly not so easy trying to understand why the deflation message came after inflation had been eradicated. We can imagine that the hard fight against the raising of nominal price increase, has put in place the deflation mechanism as a replacement. However, I would not insist on this aspect, because both deflation and inflation are messages, mere images of reality that do not participate in any way in the development of economic events. Moreover, they are images of reality even stronger when the instability of economic systems is widespread.

Apart from the hypotheses on the reason for the replacement messages, it must be said that what really matters is not so much the type of message, but rather what inflation or deflation indicate to the community. That is, the persistent global instability of economic systems. From the point of view of the defenses that monetary policy may have to protect the economic development, there is no lack of technical resources to be deployed. With quite different consequences, however, in the case of inflation or deflation.

It has already been said that monetary policy uses the monetary tightening to fight the inflation and, therefore, to induce the recession. The monetary policy in this case moves in accordance with the trend of economic inversion in the event of economic instability. Otherwise, in the case of deflation, the monetary policy is not helped by the reduction of interest rates, so reaching the zero point, due to the simultaneous decline in nominal prices. In some ways, the rate reduction until zeroing is a supine adaptation to the condition of falling prices. In other words, it cannot make any contrast action to push up the falling prices.

However, left to act under the grip of falling prices, the economy can turn towards recession, also in this case according to the market trend to rebalance, with a pause, the distorted development of the economic system. The monetary policy, however, in concert with fiscal policy, aims to avoid the fall into recession, to contain the social and economic damage due to the unemployment increase and the income contraction, especially for disadvantaged families at risk of poverty.

Obviously, we can certainly agree on the social objective. However, the question remains of the effectiveness of joint interventions committed to keep interest rates low over time and, at the same time, to inject liquidity into the market to an unprecedented extent. The declared goal of the Central Banks is to support with the new liquidity the recovery of the economy, otherwise in decline. All that, assuming that the resilience of the economic situation represents a valid support for the recovery also of nominal prices. Basically, if we manage to give some strength to the economy, the prices will consequently escape the deflation grip as well.

A hypothesis to be verified of course, which leaves behind a potential dangerous tail. In fact, the support to the economic conjuncture requires that fiscal and monetary policies play a role of mutual collaboration. However, there is no lack of adverse legacies. Public deficit spending has reached an unprecedented dimension in most States to mitigate the blows of the serious financial crisis of 2008-2009. Again, under the adverse conditions created by the pandemic, East and West are once again in agreement to widen the deficit disbursement of public budget. Well, there is no doubt that the intervention of economic policy made it possible to avoid a serious deterioration of economies during the last decade, especially by alleviating the social damage due to the unemployment abnormal increase and the rising poverty. And don't forget the negative legacy of public debt increase, with implications that still need to be examined and evaluated. (Cardoso, 1992)

In addition, the debt issue becomes a minefield for the concurrent action of the monetary policy, which seems to play a role in supporting the fiscal policy, while its action should be to act according to a long-term perspective. In fact, Central Banks are not subject like governments to the evaluation of voters and to the requests of social representation. Actually, by 
relying on the objectives of their action to defend the employment ${ }^{2}$, the Central Banks end up moving in the wake of the fiscal interventions, with the credit promotion and largely providing new liquidity. Well, we cannot ignore that during the bad storm of the financial crisis, the promotion measures of the Central Banks are essential to allow an attenuation first and then a recovery of the economic cycle.

Even in this case, however, is not lacking the hidden negative aspect, which is added to that already observed for the public debt increase. In fact, the liquidity unlimited increase and the dropped to zero interest rates fuel the prospect of loans at a zero or almost zero cost, which encourages the debt of companies and households. In other words, the system gets into debt beyond any real probability of repaying the borrowed sums. Moreover, is activated in this way a speculative credit that can push the capitalization of stock exchanges and assets far beyond the correct market value. ${ }^{3}$ (Raines, 2008)

Therefore, there could be some unexpected implications of intervention policies, which however are not advising against their strategic use in the event of a serious crisis, as also in the case of a weak economic situation. Well, some doubt is advisable about the hypothesis that the upturn could be a remedy for deflation. Actually, there appears to be no relationship between economic recovery and declining deflation. Also because the trend towards deflation affecting today the global economies, means in summary that the trend towards the global recession is spreading. In fact, the message sent through deflation basically means that the economy is far from the compatibility path; moreover, means that the correction through the recession is a necessary pause in order to regain the growth stability.

Therefore, it would make no sense to say that the rising economy disarms deflation. Now, on a practical level it's clear that forcing the economy while in deflationary conditions means going against the natural order, which proposes a pause to rebalance the economic system, with ambiguous results, anyway. In the USA, President Trump attempted to force the weak cycle at the beginning of his term through a tax legislation that reduced taxation for the three-year period 2019-2021, mainly benefiting the richest taxpayers. After a cycle rebound during the first year of its implementation, the global economy then met the pandemic, and the widespread lockdown for some months has generalized everywhere an increase in unemployment and recession. On the other hand, even the rising economy recorded over the two-year period 2018-2019 was rather an advance of the economic conjuncture than a lasting and effective recovery of the US economy.

\subsection{Some Considerations on the Inflation in the Case of Economy Tending to Deflation}

About a possible rising inflation (anyway low) in the case of a positive cycle, the experience shows that a modest inflation rise may occur during the economic recovery. In this case, we can see that inflation is approaching $2 \%$, that is the base

\footnotetext{
2 The Federal Reserve's Dual Mandate. The monetary policy goals of the Federal Reserve are to foster economic conditions that achieve both stable prices and maximum sustainable employment.

${ }^{3}$ We have also made important changes with regard to the price-stability side of our mandate. Our longer-run goal continues to be an inflation rate of 2 percent. Our statement emphasizes that our actions to achieve both sides of our dual mandate will be most effective if longer-term inflation expectations remain well anchored at 2 percent. However, if inflation runs below 2 percent following economic downturns but never moves above 2 percent even when the economy is strong, then, over time, inflation will average less than 2 percent. Households and businesses will come to expect this result, meaning that inflation expectations would tend to move below our inflation goal and pull realized inflation down. To prevent this outcome and the adverse dynamics that could ensue, our new statement indicates that we will seek to achieve inflation that averages 2 percent over time. Therefore, following periods when inflation has been running below 2 percent, appropriate monetary policy will likely aim to achieve inflation moderately above 2 percent for some time.
}

In seeking to achieve inflation that averages 2 percent over time, we are not tying ourselves to a particular mathematical formula that defines the average. Thus, our approach could be viewed as a flexible form of average inflation targeting. Our decisions about appropriate monetary policy will continue to reflect a broad array of considerations and will not be dictated by any formula. Of course, if excessive inflationary pressures were to build or inflation expectations were to ratchet above levels consistent with our goal, we would not hesitate to act.

The revisions to our statement add up to a robust updating of our monetary policy framework. To an extent, these revisions reflect the way we have been conducting policy in recent years. At the same time, however, there are some important new features. Overall, our new Statement on Longer-Run Goals and Monetary Policy Strategy conveys our continued strong commitment to achieving our goals, given the difficult challenges presented by the proximity of interest rates to the effective lower bound. In conducting monetary policy, we will remain highly focused on fostering as strong a labor market as possible for the benefit of all Americans. And we will steadfastly seek to achieve a 2 percent inflation rate over time. New Economic Challenges and the Fed's Monetary Policy Review - Speech Chair FED Jerome H. Powell 
value indicated by Central Banks as a signal for a healthy and balanced economy. Now, it appears quite evident that in a world struggling with widespread deflation and therefore with economies generally unstable and in search of compatibility, the possible position of inflation near the base value is only an algebraic fact, which in no way represents a symptom of a balanced economic state.

Actually, we must remember that a base inflation close to $2 \%$ is just an ideal value, which postulates an economic system for a long time balanced and which develops in a compatible way with the nature embracing all of us. Therefore, the base inflation close to $2 \%$ can be configured as an absolute value, like all the other great constants of physics and mathematics. Given this characteristic of absolute constant, the base inflation is close to $2 \%$ but doesn't come close to zero in the case of a stable economy, because the prices are the messengers of the economy. Therefore, the small difference of base inflation from zero is just the symptom of a sort of "background noise" produced by the economic activity when moving in full balance with nature. Background noise that is reflected on stable and balanced prices through a small alteration, which on the theoretical level has been set close to $2 \%$.

Therefore, assuming that the base value of inflation cannot be zero, it isn't equally clear and obvious how and why the base value could be set close to $2 \%$. That is, why having reached this state of stable and long-lasting prices, we could reasonably say that the economy reached the level of balance and compatibility with the development of nature. The condition to be respected in order to affirm that we have actually reached the balance point of the economic system, is linked not only to the real achievement of the basic objective but also to the economy firmly linked to that balance point.

Alternatively, having only briefly touched the base value of inflation close to $2 \%$ isn't at all a confirmation of the good administration of economy. Rather, it can be a symptom that the economy is unstable and then subject to deflation, which is pushing values down: we take note that deflation is a continuous and constant correction of values downwards. Therefore, the constant trend of increasing inflation according to an acceleration that depends on the instability degree of the economic system, is continuously narrowed by the parallel action of deflation. In other words, the economic system inflation is somewhat cut and reduced by deflation, which pushes the price wave towards minimum or even negative levels in relation to the instability degree of the economic system.

Therefore, the base value close to $2 \%$ of the baseline inflation of a stable and compatible economy depends only on the background noise of the economic system, which is assumed to be equal or close to $2 \%$. The real inflation created by the stable and compatible economic system is therefore zero. It follows that the baseline inflation close to $2 \%$ is an ideal value, anyway difficult to be found in the normal economic events, which cannot be defined with an algebraic criterion. We can consider it as a sort of constant that ideally represents the point of maximum consistency between the human adventure in the economic field and the planet evolution together with the nature embracing us. A value universal and hypothetical, without any evidence in the real life that must be related to the constants of physics. The economic mechanism does not transmit any impulse to prices, in the sense that the compatible economic activity does not generate any signal for the price formation.

Experience seems to show that the inflationary motion generated by the unstable economic system is a continuous process that has a background acceleration depending on the unstable condition of the economy. This background acceleration therefore undergoes an alteration in relation to the state of economic instability. Thus, we can see variations in the nominal run of increasing or decreasing prices according to the degree of the economic system instability that worsens or tends to recover.

Moreover, the conjuncture cycle motion affects this mechanism, in the sense that the background noise generated by economic activity on prices can be changed by virtue of the cycle direction. Not surprisingly, the background noise can be variable: this happens in the case of an unstable economy and is one of the anomalies of the instability sub-world. Again, not surprisingly: because the constant level of background noise is a specific prerogative of the long-lasting economic compatibility and is placed, as already said, at the level indicated by Central Banks close to $2 \%$.

The phenomenon is obviously relevant especially in the case of an economy with a tendency to deflation. As already mentioned, deflation acts in subtraction from the underlying motion of current inflation; therefore, usually the economy suffering from a tendency to deflation shows a rate close to $1 \%$, which becomes negative when the economic system instability grows. The economic conjuncture, where the conditions exist for a cycle recovery, can alter the inflation rate, which therefore undergoes a modest increase under the pressure of the new rising tensions in the economy. It is therefore a simple algebraic motion of prices that may therefore undergo a slight increase (e.g. up to 2-2.5\%), which could just be an expression of the variation in the background noise. With the cycle reversal, the inflation rate tends to fall into the previous position close to zero.

Central Banks connect the success of economic support to a better price climate, which would thus tend to climb the deflation slope in the presence of a robust economy. As we have said, a solid economic growth has an impact on prices tending towards deflation, which therefore show a modest rise. However, as we said, the evident factor acting in this case 
on prices is the background noise, which can increase its intensity to touch or even exceed the inflation base value close to $2 \%$. In the case of an unstable economy, such as one struggling with deflation, the background noise of the economy possibly overlapping the value of base inflation close to $2 \%$ is nothing more than a confirmation that the economic system remains in deflation. This is excluding any hypothesis that touching the value of the price constant, could be a positive signal on the way towards economic compatibility.

It's obvious that the call into question of a potential (low) inflation rise by many Central Banks, under the impulses of the recovering economy, does not mean that the slightly rising price index could somehow prelude to a passage into a world free from deflation. When reporting this possible modest result of the economic downturn on weak prices - which anyway occurred - no interpretation of the phenomenon is given in any way, which is then presented just as an objective fact: in the secret hope that a continuation of the phenomenon could over time get us out of the trouble. Unfortunately, this is not true, for the simple reason that the deflated system naturally tends to go into recession in order to overcome the consequences on economy, caused by the deviation from the compatibility path.

\section{Method}

\subsection{The Economic Cycle Is a Sign that the Economy Deviated From the Stability Path}

We have already said that, in the case of instability, the background noise assumes a variable value depending on the economic strength, increasing with the recovery and decreasing with the recession. This anomaly clearly distinguishes, also for its consequences, the world of stability from the sub-world of instability. In fact, in the stable world the background noise tends to a base value fixed and constant over time close to $2 \%$ without any possible alteration, providing the guarantee that the economy is moving within compatibility.

Well, this dystonia appearing in the unstable world is the symptom and the source of the most complex motion involving the economy: the conjuncture cycle. Therefore, having left the path of a constant and balanced growth, defined by a potential for constant and moderate growth, the instability sub-world develops according to a sinusoidal motion of ups and downs, recoveries and recessions. As already mentioned, this procedure opens the doors to the recession, which over time is somewhat able to contain imbalances and to bring the altered system back to stability.

It's the interruption of the background noise constant that defines the new levels, increasing or decreasing, assumed by the economic situations over time: a variable value which regulate or give the signal for the formation of the basic inflation that, being altered, characterizes the systems according to their instability state. So, we can argue that with the increase in the background noise of the economy, the economic system tends to accelerate the current inflation motion. A process that expands according to an acceleration that is independent from the economic situation, but nevertheless is correlated to the instability degree.

In the case of deflation, we must assume that the tension produced by the background noise of the economic system gradually decreases, so imposing to the nominal prices a downward path. The inflation underlying motion is therefore tending to contract and gradually pushes the price nominal values towards a minimum. It could be considered somewhat slow the work of the normal acceleration process, for the progressive decrease of inflation from the peak reached. Therefore, we can see an intermediate period between the inflation wave and the deflation stagnation during which the inflation can drop to lows of $5 \%$ or even less.

At this point, experience seems to confirm that inflation was defeated and therefore we moved back to a price run under control. This more or less long period of relative stability, however, tends to end with the further decline of inflation base rate below the base value close to $2 \%$. As saying that even with a long or very long parenthesis we passed from the phase of increasing inflation to the phase of deflation.

Basically, the prices passed from the inflation of sixties and seventies to the stagnation of nineties and to the start of a pronounced trend towards deflation: their long adventure seems to describe quite well the price course during the last fifty years, at least in the industrialized West and in the USA. It could therefore be assumed that during this half century we have only been able to record a change in the presentation model of monetary anomaly, from inflation to deflation.

As saying that the long battle undertaken by the monetary policy to correct the variability of nominal prices, in short, was unsuccessful. Or rather that the long battle started since the seventies by the global economy to bring the accelerated wave of nominal prices back to controlled values, did finally manage to calm the impetus of rising prices, though with mixed results. But this apparent success seems to be rather the cause that shifted the run direction of nominal prices from acceleration to deceleration.

As already mentioned, deflation and inflation are messages that the system, altered and out of compatibility path, sends to inform the community that things in the economy are going bad. Not only are they just messages but, as such, they do not participate in the economic events. They are therefore not directly attacked because they are just ghosts, a sort of mirrors in which the economic state is reflected, and their image doesn't participate in any way in the system motion. 
It could also be said that the transition period from the inflated to the deflated world, which lasted about twenty years, may have been a period of relative calm in the relationship with nature. This interpretation seems to be supported also by the clear improvement of the global economic framework, by the step forward towards a global redistribution of resources between continents, with China and India in evidence, by the development acceleration in the USA with the Reagan presidency and in the nineties during the Clinton presidency, and last but not least by the strong presence in international trade of Germany, together with China and Southeast Asia.

Even on the basis of this interpretation of the final twenty years of the twentieth century, we can say that since the beginning of the twenty-first century a new and more pressing instability, which is the origin of the formation of the worldwide real estate speculative bubble, replaces the compatibility acquired in the previous period. This bubble burst in America at the end of 2007 and then showed its full potential the following year in Europe, Latin America, and part of Asia. Essentially, the formation of the speculative bubble and the subsequent financial crisis, not lower than that of 1929 in terms of impact on the economic motion, must be understood as the failed attempt to continue the happy season of the previous twenty years. A season that instead was over and a period of pause would be therefore needed.

Basically, when monetary and fiscal policies learned to contain the inflation outbreak, which was troubling the industrialized West for over twenty years, the monetary message changed its sign: from an accelerated price motion to a decelerated price motion. It's difficult therefore not to connect the two phenomena of acceleration turning into a price deflation trend, though if remains unclear the underlying reason that could justify the economic situation passing to slowly falling prices.

Nevertheless, in any case both monetary messages, inflation or deflation, are the precursors and companions of the economic cycle. Both are precursors of a development cycle that is weakening and is then introducing the periodic recession of the economic system on the development path. Instead of a constant and slightly rising growth, which is the salient feature of the economy when is stable and compatible with nature, the basically growing development line begins to twist, so losing its strength. The logic governing the change is aimed to introduce into the development path a pause, a recession, which would limit the economy strength. A pause that, also on a logical and simply intuitive level, implies the opportunity to limit those development forms that are partly in opposition to the compatibility path.

We can define the compatibility relationship between humanity and nature around us as a model involving the nature preservation for future generations, rather than the exploitation and destruction of natural resources. Assuming that natural resources are the source of life, the preservation logic should be interpreted as the endless chain of life from generation to generation. Not for its own sake, but as the intergenerational journey of mankind in its search for the secrets guarded by the nature around us. In some way, the life is protected by the nature embracing us: in this way, we have the possibility to continue our research in the scientific and cultural fields.

If the compatibility relationship is flawed, it does not mean that the economic system will automatically show the instability signs typical of the instability sub-world. Because there is certainly a sort of elasticity in the balance of the man-nature relationship, which allows not to stop the development and progress of science and culture, despite that flaw. It must be added that this continuity in the science and knowledge evolution is indispensable, on the assumption that the civilization degree is affecting also the relationship with nature. In the sense that a greater degree of culture and civilization should mean that we are moving on a development line that is increasingly consistent with our basic obligation to respect the nature.

Thus, we must admit that the development line of the economy is marked and also limited by the obligations imposed by compatibility. But this limitation does not affect instead the push towards research and knowledge that wouldn't be stopped by some troubles in the relationship between humanity and nature. As saying that, having reached a certain stage of civilization, a constant acceleration of research can be observed over time together with its effects on the economic world.

In the sense that the science and culture development is the essential prodrome to gradually extend the paradigm of respect for nature to the whole humankind. Now, since the scenario of the global economy shows some diversity in the development and participation degree of the scientific progress, it's clear that the natural tension is moving towards a gradual rebalancing of the differences in the civilization level between the continents. This is the key to read the great run that since the last century has marked the Asian continent development, in particular China and India. An unprecedented development profile of the economy, culture and civilization level that has no equal and that finds its deep motivation in the natural tendency towards rebalancing the potential of culture and scientific research between the continents.

It must be added that the rebalancing process between continents is far from completed. While reached in fact an unexpected height in some Asian countries that are today protagonists of the world development, it's still in progress for many African countries, for Latin America and for the Near East. Since the progressive rebalancing of the development potentials of the economy and culture is an irreversible natural process, it's easy to believe that it will continue according 
to times that we cannot imagine; nevertheless, that process will gradually be implemented according to the times of nature, which do not correspond to our human times.

\subsection{The Economic Cycle as Rebalancing Asset, Rather Than Negative}

The relationship between humanity and nature is currently unbalanced. However, the life relationship seems to offer some flexibility that could somewhat mitigate the consequences due to the cracking of the compatibility relationship. In the sense that experience shows that abrupt interruptions or at least the sharp slowdown in development can start a period of relative tranquility and increasing economic development. So, after the Second World War, the reconstruction and recovery phase after the catastrophe was long and lasted until the 1960s. The same happened after the long season of the inflated world that continued until the mid-1980s. From the relative disappearance of inflation and accelerated nominal prices, began a season that lasted until the beginning of 2000 with a relative economic calm and a sustained development.

These brief considerations give us the occasion to consider the recession phenomenon in economic systems as a natural tool to correct the instability and as a mechanism to regain the compatibility of altered economic systems. In other words, the economic system experiencing difficulties in the compatibility field seems to use the recession pause as a weapon to regain the balance. According to this point of view, the economy that entered the instability sub-world, would immediately show a degradation of development potential and the tendency of economic systems to recession. Therefore, between the periods marked by greater balance and the periods marked by instability, a big difference will result from the different ability level of the economy to follow a growth path.

This diversity is measured by the presence or absence of the economic cycle, considering that the recurring economic cycle puts the recession on the growth path of the economy: that is, the periodic pause with a variable frequency which is imposed in order to clear away all the waste that is causing instability. The economic cycle is not characterized by a constant progression of recovery and reversal phases, but rather by a great variability in its behavior. For the simple reason that the shape and acceleration of the cyclical phases are governed by the instability degree of the economic system. In the sense that it is a sort of drug given in different doses according to the deviation degree recorded by the economy in relation to the compatibility path.

It is therefore inevitable that to expect a constant development of cycles is an optical illusion, due to the experience we maybe had during the initial phases of instability. Thus, in the 1960s, the Western world emerged from a long season of sustained and constant growth, which was extended since the end of the Second World War. That season was over, and inflation was beginning to appear into the world economy. A modest inflation under control, at the time was the signal that the economy could not afford the previous growth rates. The world, after the reconstruction phase, was entering again the instability sub-world. During this initial phase, the inflation remains under control and the economic cycle seems to follow a constant behavior, with rhythmic phases of peaks and reversals. In other words, in the initial phase of instability, the losses in efficiency and growth rate are somewhat contained.

However, since the early seventies the inflation was in acceleration, a sign that the untreated system instability was increasing. The acceleration of inflation caused by the first oil crisis could have had a temporary impact, in the case of an almost stable economic system. But in the context of that time marked by a widespread instability, the boost offered by the unexpected and massive increase in oil price triggered the high inflation, also due to the attempts to contain the damage deriving from the unexpected oil increase with the use of public spending. With the result of accentuating the instability degree of economic systems. Thus, the unexpected oil increase has become a factor causing an accelerating inflation. Therefore, a temporary factor of rising prices due to the oil cost had become an engine of the nominal inflation acceleration, now difficult to keep under control.

Therefore, the economic earthquake imposed by the dramatic oil increase wasn't the engine of inflation, but just a strengthening factor of the phenomenon, due to the attempt to hide the real effects caused by the cost of raw materials on the economy. Actually, even a massive increase such as the one that caused the first oil crisis should have imposed a generalized price increase that would led to a new, once again stable price structure. However, in an unstable reality and with an accelerating inflation due to the misguided attempt to maintain high the level of a weakened economic growth, the oil cost increase was a shock, which we tried unsuccessfully to calm down by containing its impact on the economy. In short, the cure was worse than the disease, so that the pressure on development and the attempts to mitigate the impact of oil crisis on the economy have instead widened the instability of economic systems. That was the real reason for the inflationary pressure increase on prices, which then continued for a period of twenty years at a global level.

Inevitable therefore, throughout the inflation period, the fall of the economic potentials and the trend towards recession, with some peaks at the outbreak of oil crises, in the mid-seventies and at the end of the decade. We must therefore admit that the falls into recession are accompanied by unexpected or anyway different conditions that modify the current framework, so becoming an opportunity for a corrective reorganization of the economy. 
It's therefore difficult to try to escape from the natural correction mechanism, which uses the economic cycle and the recessions to contain the deviation from the compatibility path. As in the seventies and more recently on the occasion of the serious financial crisis in the first decade of the 2000s, the conditions will be created - also due to instability - that will make even a hard recession, required for the correction.

On the other hand, precisely because of this need to clean up the altered system, the size and power of the recessions will be of varying strength, therefore more or less intense in the elimination of virtual excess of forced development. Based on these brief considerations, we can expect that the exit from the pandemic, which now has a global dimension, may be different in the various economic systems. According to this theoretical view, the weaker countries are financially the harder they will be hit. As saying that the term "weak finance" is addressed to those countries showing a more marked tendency to deflation. In other words, the 'deflation thermometer' can reveal, in summary, the instability degree and therefore the correction level needed to restore compatibility.

The fact that the economic cycle is not constant and repetitive over time but is a sinusoid with a dimension variable and controlled by the instability of systems, obviously brings some value to the thesis that the conjuncture cycle is a cure. That is, not just a typical factor of economic life but a superstructure that comes into action only in the case of a deviation from the compatibility path. Of course, the presence of a sub-world in which the economy enters to be purified through quarantine would mean however that economic life, just like the matter and its forces, is subject to inflexible rules of natural order; rules that are the necessary prerequisite for the human survival on this planet.

All this, to say that some natural rules and behaviors concerning economic and social life cannot be explained according to our deductive reasoning, precisely because is lacking a source to which we can refer as engine of the economic mechanism. On the other hand, according to this point of view, it's really meaningful that the events, starting from the economic cycle and the messages to the community on the economic state (inflation and deflation), are repeated over time with different intensity, but according to a highly repetitive scheme and without any apparent direction.

A repetition that is never constant but undergoes variations over time, as we have seen at the time of great inflation in the seventies. In those years, the change in the inflation rate was simultaneous with the change in the economic cycle, which obviously was at its maximum coinciding with the two oil crises. A coincidence of the cycle negative peak with the unexpected increases of the oil price, which wasn't due to the emphasis of nominal prices, but to the greater economic instability, which was also linked to the unexpected rise of the oil price.

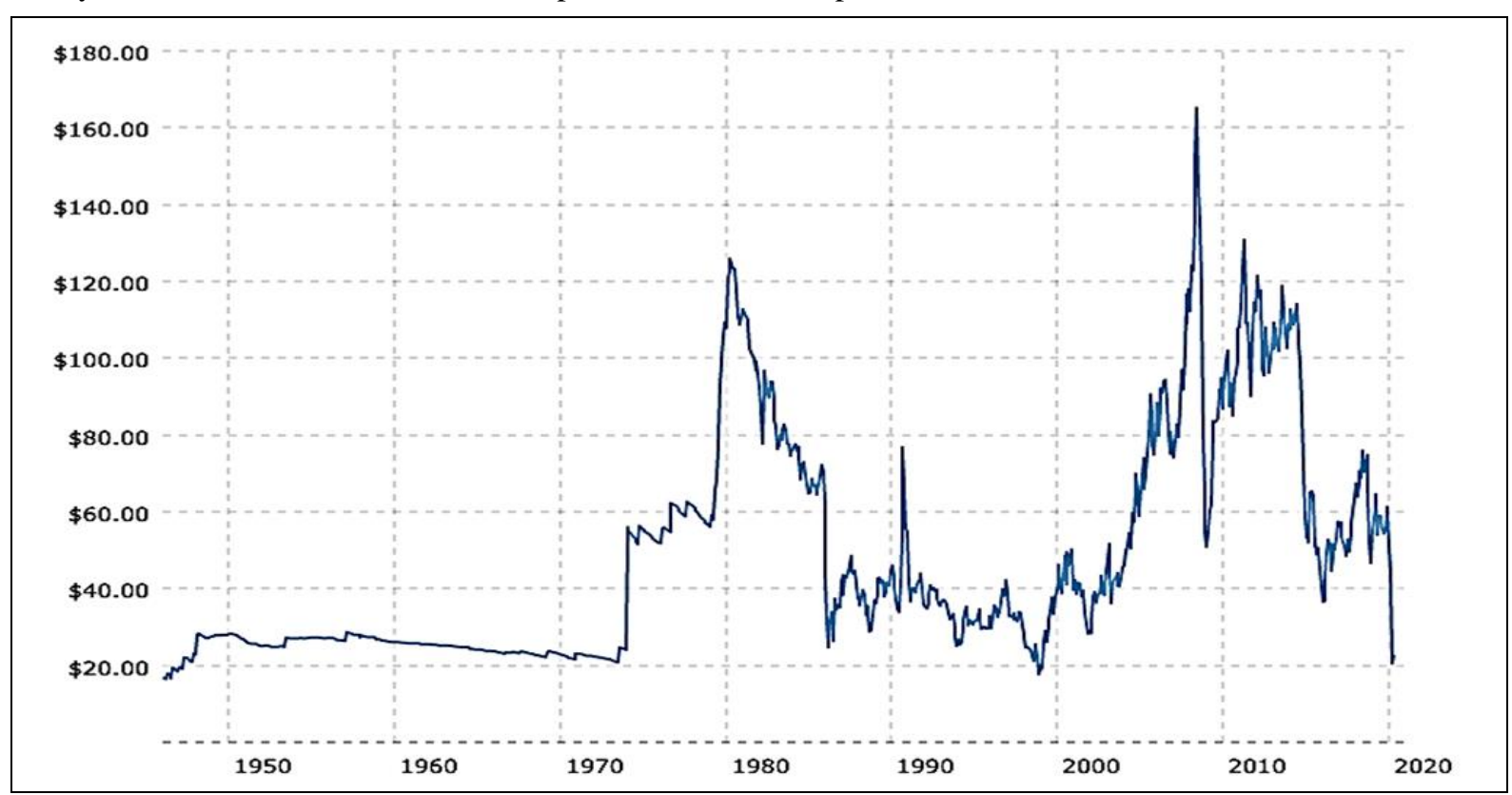

Figure 1. Oil price trend 1950 - 2020 corrected with inflation

Source : https://www.quotidianomotori.com/ 


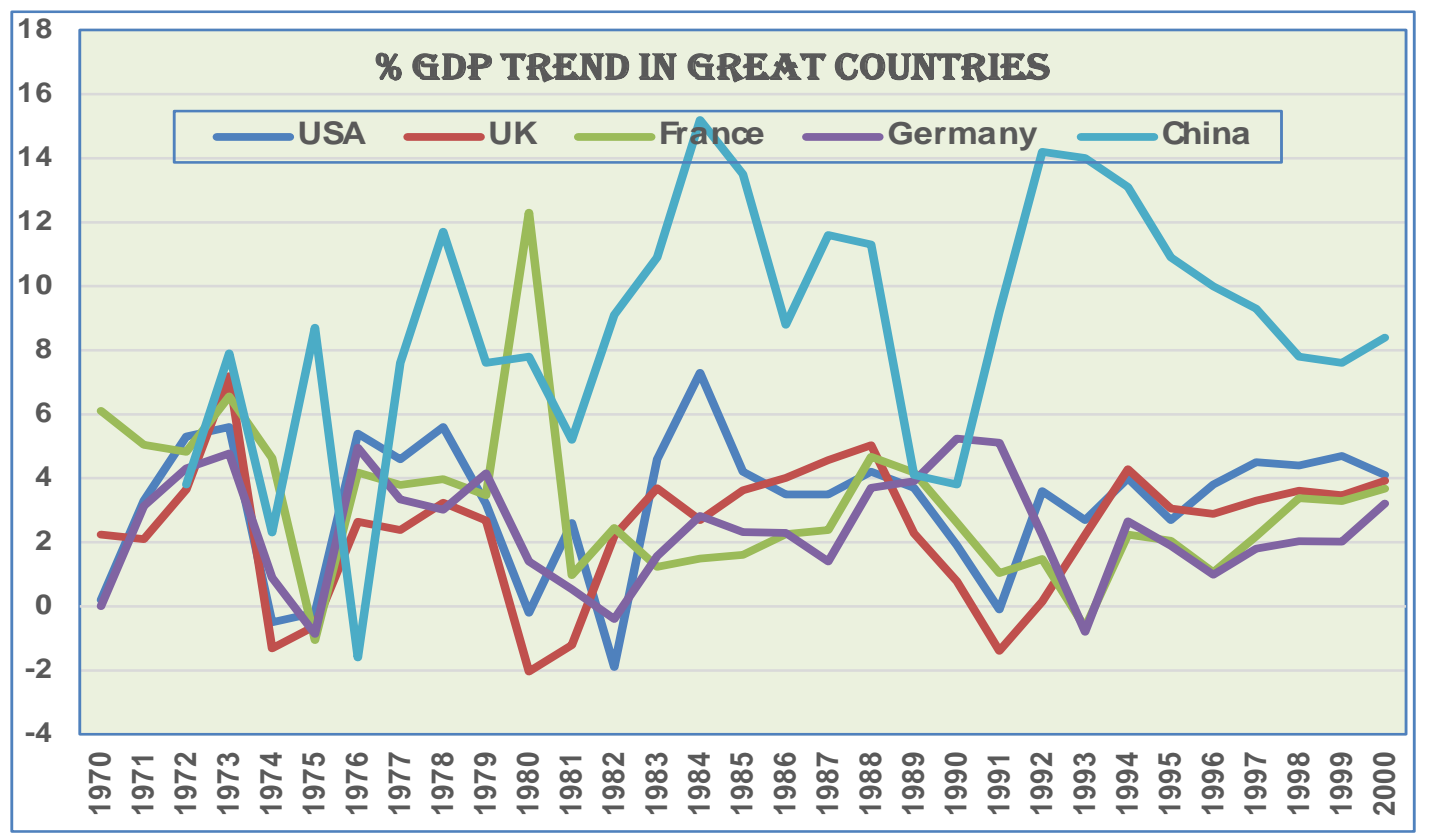

Figure 2. GDP trend in great countries 1970 - 2000 (in percent)

Source: Elaboration on OECD data

\subsection{Natural Stability and Economic Control Policies}

Since the base price value is altered, inflation or deflation are the messages informing the community that the economy is out of the right path. In any case, therefore, the economic systems show a current inflation depending on the level of the economic instability. In the case of deflation - which concerns us closely - this current inflation is low or extremely low and can even drop below zero in the case of severe financial instability. Well, in the case of speculative excitement of the economic cycle, in a context of low inflation or tending to deflation, the underlying current inflation may undergo a modest upward push, so that inflation (e.g. at 1\%) under this modest impulse can get around 2\%: therefore, we are quite near to a base inflation close to $2 \%$ although there is no way to express a compatible balanced value. We are rather facing a mere algebraic result that is certainly unable to give any answer to the search for balance and compatibility in the economy. Nor, on the other hand, can this represent a relief for Central Banks struggling in the search for a stable and real escape from the deflation grip. (Shilling, 2001)

Deflation is not directly attackable because it's just a message about the troubled economic system. Therefore, the problem of deflation becomes an unsolved problem if it's not understood that the negativity is not lying into deflation, but rather in the instability of systems. Moreover, we should understand that to solve the problem, the common remedies based on fiscal and monetary policies may not be able not only to solve, but even to mitigate the complicate issue of frozen prices. In other words, trying the classic way of monetary policy measures to reduce the money cost to zero and making new liquidity available, can be a good aid to avoid or contain the damage of an economic depression. However, this kind of actions wouldn't be able to solve the deflation problem.

We should consider that deflation is a signal that the economy has become unstable. If we let the natural correction unfold its action, the pause or the recession can over time mitigate the unstable state of economic systems. In fact, the unstable system undergoes a deep modification: instead of the constant and slightly rising growth, typical of the natural development in balanced systems, it's subject to the conjuncture cycle, which introduces the recession into the scenario, intended as a natural mechanism to correct the instability. The deflation trend can therefore be interpreted as a signal that the economic system tends to recession, to have a pause in the economic growth process.

Well, forcing economic systems to avoid the recession may be contrary to the natural trend and therefore this could mean to extend the unbalanced state over time. According to this point of view, only apparently drastic, the therapies based on fiscal policy interventions to support the economic situation cannot be rejected too strongly: even at a first rapid analysis, a contrary over-reaction should be avoided.

In fact, we are moving into a reality that is focused on the belief that the economy grows according to an alternating motion. Therefore, it seems correct to try to stimulate development and "redress" the economic cycle in order to make it grow according to a midline, so avoiding as much as possible the recession negative wave. Following this approach, the 
recession would not be the price to pay for the deviation from stability path, but rather an accident on the development path, almost a disease, to be treated by any means. Well, according to this perspective, the fiscal policy becomes the essential tool to keep the uncertain trend of the economy under control.

Therefore, when the economic situation abruptly collapses under the unexpected blows of a financial crisis, as happened in the years 2008-2009, it becomes essential to face the impending decline with its serious social effects. The theoretical discussion on the reasons that blocked the economic development, at that point are sidelined. Although we must note that is precisely this indestructible desire of the communities that the government of the economy may guarantee a "tomorrow no different from today", which after all pushes to activate any possible intervention to control the fall of the economy into the crisis. (Krugman, 2008)

This scheme of controlled economy seems, therefore, inspired by a remarkable rationality, though we should consider that the economic waves, especially those deriving from speculative processes, are actually created by the intervention policies. Nevertheless, those interventions with the aim of reducing the troubles of the economics are actually blocking the natural correction and thus impose a scenario of cyclical alternations, faced with a natural economic landscape which is following a constant and linear development.

It would be precisely this deep and ancestral common wish for the economy smoothly evolving and for a "tomorrow no different from today" that confirms the real meaning of this aspiration. In all living beings there would therefore be the innate notion of constant and linear economic growth, so confirming that the compatible economy does not need any director or economic guides, but can follow a stability path over time, if the environment compatibility is respected.

Confirming the thesis that the economic conjuncture is a modality of the instability sub-world, there is also the peculiar skill we can observe in our neighbor as also in the common man. Well, our neighbor is not an active protagonist in economic matters and yet he shows to have a summary and concise knowledge, but anyway adequate, of the economic state in a particular country. He can take the same information that everyone has through the prices of their daily purchases and through the implicit sensations becoming more real and sensitive as the economy turns towards instability. Therefore, the primary information comes from the monetary messages (inflation or deflation) continuously sent by the system when the stability path in the economy is lost.

On the other hand, if we investigate more deeply, we will be able to observe that our neighbor, even if not involved in the work of economy management, is able to formulate, though in general and synthetic terms, a sort of program to return to stability and compatibility in economics. It's actually only for these innate abilities to perceive the economic condition, that we can justify the basic idea of participatory democracy which entrusts the community with the role to choose the leadership entrusted with the economic governance. It's through these community skills about the economic state, that the collective thinking expressed by a community is used to conduct the economic surveys on production and consumption.

All this seems to be based on the ability of a community to foreshadow the difference between the ideal condition of linearity and constancy in development and the present state with the alternations of the economic conjuncture. A present situation that is outlined according also to messages not explicit but based on feelings somewhat generalized inside the community. Well, this singular ability essentially makes the community the terminal of the relationship between humanity and nature; terminal that obviously collects the signals on the divergences of the economy from the natural state, as a synthesis of the feelings developed by all the members within the community.

Well, we must admit that the economic activity moves according to physical laws: these rules are the limits that monitor the consistency of the economic course with the goal of preserving natural resources for the survival and subsistence of future generations. Are obviously included the rules that avoid the degradation of the natural system, by modifying the otherwise constant linear path of development, with the introduction of the conjuncture cycle. (Cossiga, 2018)

How else to explain the corrective behavior of the economic system moving with the simplicity of a motion that from uniform becomes alternate and, in this way, inserts a periodic pause in the development mechanism to relieve the economic system from the waste produced by incompatibility. Not only that, because the introduction of alternating recoveries and recessions varies over time according to the degree of economic instability. The correction therefore relies on a sort of internal clock that modifies and possibly extends the recession times, according to the level of instability degree defined by the natural instrument.

We should consider that the simplicity of the corrective system has no other aids to perform its function. In fact, everything moving around the mechanism, which makes the growth process of economic systems vary from linear to alternate, does not perform any cooperative work. It's only a representation of the no longer linear motion of the economy, in order to provide a generally noticeable message about the anomalies of the process. They are only representations, therefore, just like mirrors in which the economic motion is reflected without any possible participation.

Therefore, the system elaborates a series of mirror functions that are responsible for providing synthetic information, even 
with some advance, about the state of the economy, through the price engine, which measures - like a thermometer - the state of malaise of the system. Certainly not for its own sake, but to inform the common man that the economy derailed from the stability path. And again the purpose is well defined: to provide all the community members with advanced information on the quality of the economy governance, to move when necessary the protest and to dissent from the policy implemented by the leadership.

So, we have an intervention with two levels that are not overlapping because they are only the representation of each other. This second collateral tool doesn't participate in the correction, but has obviously the purpose of inducing a change in the economy governance, when it's damaged the general rule set in the DNA of every living being, which postulates a linear and constant growth of the economy.

\section{Result}

\subsection{The Policies to Control the Conjuncture Cycle and the Concomitant Actions of Natural Correction}

As we said, when the deflation message appears, the community has a first report that things in the economy are going bad and that instability must be treated. Without interventions by the action policies to support the conjuncture cycle, the economic system would slowly tend towards recession to have a sort of purification pause which would allow the recovery of compatibility and balance. The economic cycle would not in fact be a curse taking away the opportunities for a linear and constant development. It's instead a safeguard mechanism which, if left to act, can allow to recover the linear and constant growth path that we have lost. It's a bitter medicine but can become even worse if we act in contrast to the natural mechanism. Anyway, it's painful on a social level because increases poverty and mainly affects work. And thus, the result is the accentuation of inequality in income and wealth within the community.

For these reasons, the intervention and support policies for the economic situation have the aim of mitigating the cycle especially when it's violent and profound, in an attempt to skip this phase, that actually we know to be curative, and thus starting a mere imitation of the linear and steady growth of the balanced economy. Now, it's evident that the defense against the deep crisis becomes inevitable to avoid the social and economic damage that would push back development motion. On the other hand, in the midst of a negative economic trouble, such as the one we experienced in the 2008-2009 financial crisis, the defense implemented by fiscal policy, with the unparalleled expansion of deficit public spending, has shown a great effectiveness in fighting the cycle collapse. Moreover, in perspective it has given some breath to the economy, so allowing a recovery in activity, though at moderate levels, anyway lower than in the previous decade.

However, a question remains about the possible dark side of the continuous and increasing use of economic support policies, because it's clear that the support measures are basically opposed to the natural corrective action. This means that if we do not let the conjuncture take its course, the economic system will not be cleansed from the instability waste. Therefore, sooner or later the correction mechanism will come back again, maybe with a greater strength. But in the meantime, we will certainly see a general trend towards deflation. As saying that the economic system is warning the community that the emergency is not over and that the instability burden didn't decrease.

Therefore, it's evident that under the crisis blows the only thing that can be done is to try to repair what is possible, even if in this way the natural correction would be hindered. We should note that in the case of a sharp decline in the economic situation, as during the financial crisis of the last decade, it may be assumed that the rapid economic decline is only partially due to the action of instability correction. There is in fact the danger of a cascade fall of production activities, that would be originated in sequence due to the market progressively dried up and to cash problems as well. (Roubini, 2011)

For these reasons, we can believe that the policy supporting the cycle, in the event of a serious financial crisis, plays the role of reducing the risk of a serious economic fall, though the natural corrective function is left to partially play its role. Corrective function that is at least partially achieved through the recession, which is anyway doing some work and then is affecting the economic system despite the intervention of support policies.

In other words, it could be assumed that a fiscal policy supporting the falling cycle could play a double role. First, it could be enabled a controlled recession that should somehow cooperate to correct the growth path. In addition, it could be developed a function mitigating the excess fall of the cycle, through interventions aimed at saving and preserving companies and activities still efficient but on the edge of closure due to the sudden lack of cash and the wide market fall. We can add that the good resilience after the sharp fall may be partially due to the correction work that the controlled recession guaranteed in any case.

On the other hand, the declining efficiency of economic systems after the 2008-2009 financial crisis was probably caused by the residual unsolved instability. In the same way, this parameter of the lower efficiency of post-crisis economic systems, can be related to the various degrees of residual instability inside the various economic systems at a global level.

As we said, in the case of a deep involution of the economic system, the support policy manages to limit the damage, but cannot avoid a recession. Therefore, a natural correction process is initiated, though partial. It follows that the attempts - 
often partially successful - to keep the system in balance, thus avoiding the natural involution of the cycle, are intended just to imitate the natural condition of compatibility. In the assumption, therefore, that we are able to have the control of economic growth in order to follow the natural path. Now it's quite evident that, by operating in this way, the unstable system is condemned to a virtual development, but this improper surplus will be subject to a progressive elimination through an increased number and intensity of the cycles.

The supporting policies can therefore move in opposition to the natural cycle correcting the system that had left the compatibility path. In other words, the unstable economic system periodically requires some pauses to process the anomalies of incompatible development. In this way, the treatment progressively applied allows the unstable system to continue on the development path, although attenuated. The problems will become more relevant if the cycle control policies manage to give essentially the apparent feeling that we can bypass the economic cycle: in this way, the economy would achieve the objective of a relative calm in its path.

Now, it's quite clear that there is no way to reactivate the growth without cycles if the economy has been unstable for a long time and the instability degree is reflected by the price deflation. It follows that the choice of a continuous support to the economy, though with some appreciable results, doesn't lack a negative legacy, which sooner or later we will have to pay. It can be summarized in this way: the refusal of the recession can be compared to the refusal of a medicine, therefore without remedies the economic system remains unbalanced and with a tendency to get worse. As already said, the cycle appears if the economy leaves the natural development path; thus, the sequence of the economic cycle is introduced and in particular the recession which imposes a pause on the development mechanism. This pause is equivalent to a cure that can allow, if left to act, the instability reduction and the return to a constant and linear progression.

\subsection{The Anomaly of Current Scenario and the Role of Support Policy During the COVID-19 Spread}

The global economy is now struggling with this problem, which is causing many troubles. The deflationary trend pushes growth down, so cooling the prospects; the communities perceive the feeling of malaise raised by this general situation and as a result has grown the mistrust towards the governments that cannot find a way to resolve the economic instability. This feeling of malaise is somewhat mitigated by the prevailing concern about the pandemic problem that is currently worldwide spread. The pandemic, on the other hand, is then leading to a mandatory pause all the economic systems: so it seems that it can play the role to pause the economic systems, which is usually a role delegated to the conjuncture cycle.

This is not only a pause for the economy, but also for the governments who find, in the search for recipes and requirements for a healthy behavior during the pandemic, an advantageous way to hide the problems troubling the economy for its weak performance. Moreover, the modification of the economic outlook with increased unemployment and economic malaise offers to the supporting economic policy a role, somewhat original though common in periods of serious crisis.

The recent lockdown and the new fears for next future have created an unexpected poverty increase due to job losses and reduced activities. Economic policy was therefore called to play a substitution role, so the income cut by the pandemic would be replaced with an alternative form of social income. I consider this an essential function on the social level, which however creates an increase in public debt, committed to maintaining the social peace to contain a further and serious increase of income and wealth inequalities.

An unexpected condition, to the benefit of governments in office who saw their consensus declining due to low growth and deflation tendency; but today they find an increasing consensus for the actions being taken against the pandemic and in favor of social peace. In fact, we should consider that the social spending implemented through the increase of public deficit spending, does not meet with great criticism because it deals with an essential issue, such as providing an income to families now poor because without work.

Moreover, the rising social spending also plays the role of supporting the rapidly declining economic situation, thus mitigating those basic reasons that were causing the consensus drop of current government. It's a paradoxical situation or nearly so, that modifies the short-term political but also social perspectives. As saying that the pandemic represents a sort of plugging of the political situation, obviously as long as there is a danger to public health. It should not be surprising this political pause, because every criticism towards the excessive economic support policies disappeared and at the same time the serious decline of economic situation is justified by the general framework, which in no case is attributable to the government currently in office.

Of course, we are referring to the hypotheses of fight against the pandemic, which is carried out perhaps successfully but at least with commitment. Thus, the government is basically evaluated for the results achieved in the fight against the pandemic and no longer for the actions more relevant to the government activity, that is the success or failure of the actions relating to economic development and employment trends. Also, this asymmetry is quite consistent with the natural process of the economic system requalification. Because the natural system for the instability correction, essentially becomes the mechanism that takes over the management of deviated economic system. 
In fact, we should remember that the natural system lets the economic situation follow its fate in order to correct the instability. This means that the natural mechanism at the end agrees with the lockdown and the activity reduction produced by the pandemic. Because the activity decreases or rather its contraction produced by the pandemic is essentially forcing globally the economic systems into an anomalous recession, that is unexpected and unpredictable but dependent on natural factors outside the correction mechanism. We are therefore in the middle of a strange situation in which the conditions are being created for a natural deployment of the anomalous economic trends, which are in line with the corrective needs of unstable systems.

This leads us to believe that after the pandemic, there should be a global generalized decline in gross product, essentially in line with the natural process of correcting altered systems. We should therefore believe that, after this unpredictable but natural economic decline, we can expect a global efficiency recovery of economic systems. This means that in the coming years, when the pandemic will be over, we could count on the efficiency qualitative improvement of the economic systems. That is, we'll be able to count on a period of sustained economic growth that could be somehow compared to the 80 s and 90 s of the past century, in terms of duration and continuity.

A sustained growth in the near future, then: but what is this hypothesis based on? The basic idea is that if we let the natural correction system work, as a result we should have a reduction in the imbalance of economic systems. An unwanted but obligatory correction is underway at a global level which, however, strengthens the hope to recover in the future the economic and social losses and disadvantages produced by the pandemic.

The first symptom of the economic improvement should be seen already during 2021 through the price system that should relieve the deflation negative burden. In other words, as the rising deflation warns that the economic system has become more fragile and tends to recession, in the same way by mitigating the deflation we should see an improvement in the economic situation. On the other hand, the price decline observed in recent years, when the phenomenon of deflation acquired a global dimension, is a clear signal of the weakness and fragility of an economic system. As saying that, where the phenomenon of development degradation has been greater according to a greater deflation, we can equally believe that the expected deflation reduction may well be a good means of development revival.

\section{Discussion}

In our walk through the previous pages we talked according to a relationship between humanity and nature for the safeguarding of natural resources for the future generations. In the sense that the economic development must respect and safeguard the nature, since the natural evolution of natural system perfectly complies with the preservation of resources offered by the planet. It follows therefore that also humanity should possess the necessary qualities for this basic rule to be respected. There would be then a mutual interest between the humankind that wants to continue living in its future generations and the nature that ensures that this wish is realized. I mean, there must be a mutual interest and thus a safeguard power working both at humanity and natural level.

A complex relationship is therefore outlined with reciprocal messaging actions between nature and mankind, warning that the system has gone out of its natural path and has taken the unbalanced way. A reciprocal messaging then, where prices are the means to warn about the anomaly in the economic system behavior. On the other hand, the human communities are a sensitive terminal of the relationship with nature, so that individuals and groups are informed both explicitly and implicitly that the economy has derailed from the development path. The community is therefore invested with the responsibility of calling the leading groups to direct the economy in a way increasingly coordinated with the natural compatibility goal.

Nevertheless, it is singular that the messages sent by the nature to the community are of a monetary nature, even if these manifestations in any way participate in the economic activity. Both inflation and deflation are connection instruments between humankind and nature: they are messages informing about the status of relative relationships.

In summary, the nature provides us with a series of messages about the state of the economy, when the economic system has lost the compatibility correct path. These are direct messages such as price trends, deflation, inflation or, otherwise, implicit messages: like a sort of sensations that everyone is receiving, then processed to help us understand whether the economy has entered the instability sub-world. These are therefore messages perceived by the common man, by the man next door, by our neighbor, who - though far from the economic matters - appear fully able to give a valid opinion on the government conduct and on the public management of the economy.

The community, which is continuously experiencing the market problems, appears therefore to be able to provide as a whole a judgment on the economic management and to offer or not its consent to the government in charge about the management of economy and social sector. Thus, the nature offers a series of messages to the communities of each country, which in turn should use these messages to roughly define the most useful project in order to bring the economy back to its natural stability. A project obviously embryonic, that may or may not be in accordance with the electoral 
programs of various coalitions in the running for next electoral deadline. It will therefore be the task of the coalitions competing for the renewal of institutional offices, to give the right shape and content to their programs to make them as close as possible to the wishes of community.

Thus, strength is given to the principle asking rulers to look further for the community welfare, without fragmenting their action in short-term interventions that are useless even to consolidate the consensus to the current leadership.

The complex of relations between mankind and nature, made of reciprocal exchanges, is a fiduciary trust given to the community as ultimate holder of this relationship: essentially, it is a linear mechanism that seems paradoxically quite complex in theory. On the practical level of relationship implementation, however, the problem lies in the terminal (i.e. the community), which may not respond with sobriety and timeliness to the indications coming explicitly and implicitly from the economic system. This happens because the implementation of the mechanism requires a time even long, which is derived from the synchrony established in the relationships and sensations coming from nature and from the way they are received by the community organism. During this sometimes-long period of synchronization, the system stability can further deteriorate.

The emergence of new figures coming from the instability world can therefore be related to this problematic balance in the relationship with nature, because the natural corrective system cannot stop to wait the continuous recomposition of the balance between nature and humanity. Due to an extended instability, we can believe that some alarming phenomena such as speculative events, which were common in the previous century and appeared also in the current one, are becoming an operational reality unexpected and brutal. The imbalance between the reception of messages and their implementation, can compromise the ability of communities to express, during the electoral consultations, the candidates suitable to fully understand in the best way the natural message received through the generic and synthetic indications of the community.

As saying that the difficulties, when they do not allow the community to express itself fully and in the established times, can become a factor producing unexpected new 'monsters', quite worrying though often even little noticed. This is the case of the widening unequal gap in wealth and income distribution among the population. An unfair and devious mechanism that is felt only by perceiving the continuous poverty increase, a sad reality despite the increase in some cases of wealth and overall incomes. Thus, a general social malaise is growing, which in some way must be corrected, but which is obviously the result of a persistent instability within economic systems, when the relationship between humankind and nature for some reason is interrupted, withered, diluted over time.

\section{References}

Ben, S. B. (2000). Essays on the Great Depression.

Cardoso, E. (1992). Inflation and poverty (No. w4006). National Bureau of Economic Research. https://doi.org/10.3386/w4006

Cossiga, G. A. (2017). Stability and Instability of an Economic System: Considerations. Rev. Eur. Stud., 9, 8. https://doi.org/10.5539/res.v9n3p8

Cossiga, G. A. (2018). The Search for Inflation on a Constant Basis at 2\%. Social Sciences, 7(4), $165-181$. https://doi.org/10.11648/j.ss.20180704.13

Cossiga, G. A. (2019). The Economy of Sustainability: Some Consequences on the Economic Theory. Theoretical Economics Letters, 9(8), 3034-3064. https://doi.org/10.4236/tel.2019.98187

Cossiga, G. A. (2020). According to the sustainability theory, the natural rebalance of resources and wealth may continue in global scenario. Advances in Social Sciences Research Journal, 7(7), 927-957. https://doi.org/10.14738/assrj.77.8761

Geithner, T. F. (2014). Stress test: Reflections on financial crises. Crown Publishing Group (NY).

Krugman, P. R. (2009). The return of depression economics and the crisis 2008. W.W. Norton \& Company, Inc. New York.

Nouriel, R., \& Mihm, S. (2011). Crisis Economics: A crash course in the future of finance. Penguin Press. https://doi.org/10.1515/9781400831722

Raines, J. P., \& Leathers, C. G. (2008). Debt, innovations, and deflation: the theories of Veblen, Fisher, Schumpeter, and Minsky. Edward Elgar Publishing.

Reinhart, C. M., \& Rogoff, K. S. (2009). This time is different: Eight centuries of financial folly. Princeton university press.

Shilling, A. G. (2001). Deflation. How survive and thrive in coming wave of deflation. 
Roach, S. S. (2009). The next Asia - Opportunities and challenges for a new globalization - John Wiley \& Sons Inc. OECD - OECD Stat Database, various years.

IMF - International Financial Statistics - Database, various years.

IMF - World Economic Outlook Update, July 2018.

\section{Copyrights}

Copyright for this article is retained by the author(s), with first publication rights granted to the journal.

This is an open-access article distributed under the terms and conditions of the Creative Commons Attribution license (http://creativecommons.org/licenses/by/4.0/). 